\title{
Historical Background of Prostitution and Typology: A Social-Legal Perspective
}

Ehsan Rostamzadeh ${ }^{1^{*}}$

\author{
Rohani Abdul Rahim 1
}

Farid Mohseni²

\author{
${ }^{1}$ Faculty of Law, National University Malaysia (UKM), Bangi, Selangor, Malaysia \\ ${ }^{2}$ Faculty of Law, University of Judicial Sciences and Administrative Services, Tehran, Iran \\ *Corresponding author: Ehsan Rostamzadeh; Email: ehsan_rostamzadeh@yahoo.com
}

\section{Doi:10.5901/mjss.2016.v7n5p232}

\section{Abstract}

This article reviews the status of women in different civilisations, such as Mesopotamia and Greece. It also analyses the status of women and prostitution's types in Iran. The history of the romantic relations between men and women has been the most wonderful and complicated one in human life since creation. Such romantic acts occur in different forms, for example hugging, and are epitomised by sexual intercourse between men and women. On the issue of prostitution, different policies have been adopted by countries, such as legal and illegal prostitution. Prostitution in Iran is illegal, and incurs various punishments, but in some countries, it is legal such as Netherlands and Australia. According to this policy, prostitution is a job that must be monitored and controlled by governments and has job's benefits. There are different types of prostitution which will be presented here such as consensual prostitution and forced prostitution. This article is prepared through analytical and archival method of research.

Keywords: Women, Prostitution, Trafficking, Sexual Relations, Prevention.

\section{Introduction}

Sexual instinct has been proposed as a fact of human life. People learn about it in the course of socialising in society (Alasvand, 2006). They also learn about sexual behaviour as a set of thoughts, procedures, functions, rights and wrongs, personal beliefs, individual and family norms, as well as social and moral norms adopted by a person concerning relations between men and women, and sexual affairs (Kaveh, 2007). As Will Durant suggested, reprehensible moral abnormalities pervaded all medieval societies, despite significant variations among them in terms of laws defining sexual behaviour, including the relationship between men and women, and those prohibiting prostitution (Samadi Rad \& Saberi, 2008).

The phenomenon appeared in Egyptian history over four thousand years ago and was also prevalent among Assyrians, Babylonians and Iberians. In ancient societies, the oldest form of prostitution was more closely associated with religious beliefs. In the post AD period, parents sent their pretty girls or, from time to time, boys to temples for sexual relations involving the touching of their intimate parts by priests and votaries; a sacrificial practice believed to provide a gateway to heaven. Girls would stamp their feet and clap their hands in temples, and offer their hearts to priests and votaries. They would integrate their breaths with those of guests to strengthen the pyramid temples. Spiritual prostitution thrived over several centuries during which people believed that, by victimising their daughters, they purchased the indulgence, meaning access to heaven. (Moslemi Bidhendi, Agha Bakhshi \& Esmaeili, 2012). In this study, the data are of library type and the analytical method was used (Yaquin, 2007). The main objectives are to reach a better identification of women's status, consensual and forced prostitution in Iran, and finally, preventing prostitution.

\section{Research Methodology}

This study is a type of archival or primary research which involves diverse evidence from Iranian archival records. It has been hunted through the 32 of documents relevant to the types of prostitution and status of women in the different periods of history such as Mesopotamia, Greece and Iran. This study lies at the heart of academic and other forms of original historical studies. It also focused on the different types of prostitution in the analytical point of view. Accordingly, 
the data are of library type and the method is analytical (Yaquin, 2007). The contribution of the current study is identifying the circumstances of prostitution in Iran and better understanding of the status of women engaging this social issue, including consensual and forced prostitution in this country.

\section{Women's Status in Different Civilisations}

\subsection{Women's Status in Mesopotamia}

Generally, women's rights in Mesopotamia differed from those enjoyed by men. Women's rights included the freedom to socialise easily in public commercial places. They could also own property personally and attend social functions. In the different states of Mesopotamia, women's status varied, and changed with the times. There was a wide gap between women's rights depending on the particular class to which a woman belonged in society, from high to low. This significantly undermined women's power and independence during the Assyrian age (Rahimi Far, 2005).

The first civilisation in ancient Mesopotamia was Sumerian. ${ }^{1}$ At that time, women's power and position were further associated with temples. Young girls served as maids in temples, as concubines or as the representatives of gods on Earth (Stephenson, 2000) Fathers were also proud of serving their own daughters for the sake of religion. They, sometimes, endowed their daughters to serve in temples right from birth. In Sumerian society, prostitution by men was tolerated, but women prostitution was viewed seriously and punishable by death. This is because women were only expected to have sexual intercourse with their own husbands.

At about 1750 B.C, Sumerians, who were the creative forces in eastern civilisation, were overcome by their neighbours, the Babylonians. In Babylonia, women were men's assets. Fathers determined who could marry their daughters, and could even sell them to rich men at stipulated prices. Marriage was monogamous for women, whereas men could patronise prostitutes or get concubines, in addition to their own legitimate spouses. Herodotus observed that "one of the most offensive customs and worships in Babylon, which would attract a foreigner's attention was that each woman must go to the Aphrodite temple for once in her lifetime and expose herself to a foreign man"(Stephenson, 2000). The Babylonians believed that their girls must spend one night in the temple before eventually going to the homes of their husbands. The girls had seven valued ornaments and presented one of them behind seven doors to become finally bare before entering into the temple and presenting their divinely gifted ornaments. This was the only way of performing their religious duty (Bastani Parizi, 2001).

The next civilisation in Mesopotamian history was Assyria, which existed between 600 and 900 B.C. ${ }^{2}$ In Assyrian civilisation, there was observably significant decline in women's individual independence. During the middle part of this civilisation, almost all rules related somehow to women and imposed many limits on them. It seems that the rules were the retrieved form of Hammurabi rules in which women were classified based on the types of their sexual activities. A woman, who served a man, or satisfied his sexual needs, or who was supported by him, wore a face veil and recognised herself as the personal property of that man. Women, who were not in this position in the sense of being committed to a man, such as slave women, or concubines, did not need to wear a face veil. In effect, the face veil symbolised a free woman. In fact, during the middle period of its existence, Assyria established a hierarchical system for women in Act 40. A married woman or a single girl was atop that system. Next, was a concubine woman, whether slave or free, and in the lowest position, were prostitutes or female slaves.

Before the enactment of that Act, temple prostitutes, who were nuns for the gods, enjoyed independence and were even viewed as respectable women. However, during this part of Assyrian existence, following the introduction of Act 40, sexual services in temples were not considered an effective factor in determining a woman's respectability because temple prostitutes were viewed just as other prostitutes. In other words, whereas in ancient Mesopotamian societies, there was an obvious difference between religious prostitutes and commercial ones, in the middle part of Assyrian existence, Act 40 jettisoned that distinction. The Act classified women and undermined the position of some groups of them. Hence, this law can be viewed as one of the first signs of overt government intervention in the realm of marital affairs (Rahimi Far, 2005).

\subsection{Women's Status in Greece}

In Greece, attitudes towards women varied. Some viewed them as mothers for the citizens. Hence, they were respected.

12500 to 1750 B.C.

2900 to 600 B.C. 
To preserve their chastity, women were protected from the men's lustful look. Girls had no intervention in their marriage, which was consummated according to the wishes of their parents. Other views about women were less favourable. Symonides, a well-known writer, viewed women as animals, who had taken a human form, and as a veritable source of chaos. As he maintained, "women are sexual creatures who are not able to control their sexuality; they must necessarily be limited." Symonides believed that "women drained men of all things such as physical and sexual power, food and wealth and they were the source of all vices. But society would be annihilated in the absence of them." Most men believe that women were created only for procreation. Images of women represented on tiles are often those of dancer girls and prostitutes, implying that men attach less emphasis and importance on this stratum of society because they are pictured as slaves serving men's needs (Rahimi Far, 2005).

Work, freedom and independence for Greek women depended largely on their social position. In Greece, three classes were defined for women. First, married women, who were forced to stay at home and rear their own children. According to custom, married women were respectable, enjoying social rights, and were not allowed to appear in public, except for the purposes of offering religious services. Second, concubines whose position and status in society had not been defined. They were, in fact, slaves, widows and girls, who had been freed into society and lured into prostitution. This stratum of women was free in society and not under any constraints by virtue of any stipulated law.

Third, women who were more educated than married women. They were attendants to men at ceremonies and parties, provided they received high wages from the men. Hetaira were not only sexual attendants for men but also helped them socially and intellectually. Although they never enjoyed social benefits as prostitutes did, they occasionally played the role of wives for men. Nevertheless, children born of them were illegitimate and lacked citizen rights. They participated more freely in social activities than married women and engaged in arts such as dance, music and songs, as well as philosophical and intellectual discussions (Durant, 1997).

\subsection{Women's Status in Iran}

In Iran, while prostitution has always been a serious moral deviation, its prevalence varied within the times. For example, during the Qajar dynasty in Tehran, there were prostitutes throughout the city, acting freely. During the years before the 1979 Islamic Revolution, prostitution had also been introduced throughout the city, and it was seen as a social problem with limited prohibitions. Today, it has become even more rampant throughout the country, despite prohibitions imposed by religion, custom and social norms (Samadi Rad \& Saberi, 2008).

The literature on prostitution in Tehran before the Islamic Revolution indicates that, in that city, a special system of prostitution had been predominant, and one can identify five types of active prostitution there. These included prostitutes in New City castle (Shahr-e No); prostitutes in night resorts; street prostitutes; prostitutes in houses; and slum dwellings. Places for prostitution were destroyed after the Islamic Revolution. Shahr-e No castle was destroyed in twice 1979 and again in 1989, just as Ghorbat district in 2000 and the houses in 2003 by the police.

\section{Types of Prostitution}

Prostitutes fall under a variety of classifications based on the types known all over the world. However, most of these forms might vary within countries. Each of the main ones could be categorised as follows;

\subsection{Consensual Prostitution}

Some women resort to prostitution, depending on their own moral characteristics or other factors. For example, some do so due to their anti-social character as deviants, while others opt for it as a means of income, or in response to their sexualities. In fact, this group of women indulge in prostitution by the willing participation of both parties. That is why this variant is considered consensually. It is true that human beings have different needs, but a person whose will or choice and moral character is properly formed, would be able to resist the tempting power of instincts, greed and other vices (Alasvand, 2006).

One of the spurious features of prostitution is the desire and possibility of earning a high income, without specialised skills, such that even the lowest earnable income could be multiple times more than the attainable amount from a full-time specialized job (Fatehi, Sadeghi \& Ekhlasi, 2010).

Specifically, women who resort consensually to prostitution are perceived as;

(i) women with low IQ and physical abilities, who see prostitution as a way to enter the social scene. Such women are not appropriate cases for traffickers; 
(ii) women who see prostitution as a natural activity; these are prostitutes who inherit the job and are well aware of the nature of their activity. Also, they have a high self-esteem, and are resistant to the threats and problems associated with prostitution;

(iii) pretty and clever women, who victimise rich and influential men to earn high incomes. These are the smallest class of workers on the job, who tend to insulate themselves from the usual problems of prostitution through their chosen option; and

(iv) unsusceptible women seeking risk, and who thereby surmount social, political and cultural barriers to influence minds (Maknoun \& Ataei Ashtiyani, 2005).

Sociologists identify different types of prostitute whom could be classified under consensual prostitution. The following is a brief review of the classification.

\subsubsection{Women of the Street}

Street women are those who proceed to have sexual relations with unfamiliar men to earn income. In fact, they sell their own bodies. The State Welfare Organisation of Iran, which is responsible for the prevention of social decay, defines street women as "those who are living through selling their own bodies" (Safari, 2013).

There are different views concerning the reasons for the emergence of street women and prostitution. Although some experts emphasise economic reasons as the main cause of the phenomenon, others consider the social and mental factors more influential. Some experts in cultural problems and social pathology believe that the street women phenomenon is prompted by the desire of girls and women to escape from their own families. In other words, the main factor that underlies women selling their own bodies is the desire of girls and women to abscond from their families. In fact, they go into promiscuity not only due to economic reasons (Rahmani, 2009). Street prostitution results in many cultural, social and economic problems in society, including negative and destructive consequences at both family and personal levels (Ashouri \& Ravaei, 2010).

According to Madani Ghahfarokhi, generally and compared to the others, the group of prostitutes with less education suffer health problems more frequently, and are more prone to arrest by the police. They use more, as well as less standard methods to attract customers. Primarily, they walk in the street alone, and attract their customers in streets, alleys, waiting rooms, hotels, cinemas and coffee shops. They are usually not members of criminal bands, but they often pay money to some of them to enjoy their support. Also, they are placed in lower jobs than middle-range ones and rarely look for a new job. They establish friendly relationships with others. About $75 \%$ of street prostitutes go into prostitution through mediators (Madani Ghahfarokhi \& Roshanfekr, 2013).

\subsubsection{Brothels}

Another type of consensual prostitution relates to prostitutes who entertain customers in organised houses. Brothels are criminal places that temporarily attract offenders and potential victims to promote corrupt activities (Sharifi Khezarati, 2010).

This type of prostitution is diverse and goes by numerous names in different languages. Some brothels are independent, while others are located in red light districts in cities. Also, some are formed as groups or apartments. This is observed frequently in America and Europe, as well as other countries in which prostitution is either lawful or unlawful. In some countries, the houses are established at certain sites throughout a city by the government. At the onset,, new prostitutes learn the job's procedures, especially how to attract and maintain customers. The houses are controlled by leaders to whom $50-60 \%$ of income generated by prostitutes is given.

Those whore-house leaders are at the middle level of the job. They make probably limited friendly relationships with other prostitutes and have less right to select their customers. Women who descend to prostitution in brothels believe that they are in better conditions than street prostitutes because working in such places is safer and more hygienic. In those places, women meet other women, who may gradually become their friends, and provide them companionship. This is not the case for street women because they are forced to work alone, and are more exposed to threats, although women in brothels also have their own special problems (Mohseni, 2011). Middle-class prostitutes mostly lack career opportunities with a low level of education, and usually, have no intention of finding new jobs. (Madani Ghahfarokhi \& Roshanfekr, 2013). 


\subsubsection{Telephonic Girls (Call Girls)}

In terms of stratification, the group at the top of the sexual relations ladder is called "aristocratic prostitutes" or "telephonic girls.' They demand the highest amounts of money in exchange for sexual services and call such amounts "free rates." In most industrialised countries, the group's income equals that of high-income jobs. They are higher educated and exhibit more complicated attitudes than the other prostitutes. Wearing more expensive clothes with heavy make-up and living in more luxurious houses than conventional middle-class citizens are among their features as well. They believe in their higher social position and become offended when treated as street women and in general, do not use the title "prostitute" in describing themselves. The process of waiting on their customers is usually done telephony. They have different behavioural styles, and in public places, they relate with their customers as girlfriends and not as prostitutes. Since discretion is a part of the job, the prominent customers are not introduced to their friends. Unlike some street women, they do not steal from their customers and are not greedy. A majority of telephonic girls acknowledge that they live in better conditions than housewives and employed women. However, there are also conventional employees among them (Mohseni, 2011).

This group is ranked among the upper class of jobs and usually works from personal apartment, using telephones. They may communicate with their customers directly or through procurers. Further, they are often more selective about their customers than prostitutes in the other classes (Madani Ghahfarokhi \& Roshanfekr, 2013)

\subsection{Forced Prostitution}

The role of dealers and mediators should not be ignored in defining prostitution and its major elements. As receiving money is one of the key factors of the activity, the woman's body will automatically become a good "prey." A deeper understanding of the phenomenon will unveil another category called forced or didactic prostitution. In forced prostitution, economic needs, as well as a woman's physical body are highlighted. The more the emphasis is on qualitative elements, the greater is the likelihood of women ending up in prostitution. In the definition and discussion of prostitution, all the emphasis is on women, and not men, because the phenomenon involves the sexual exploitation of women (Alasvand, 2006)..

In such a case, the average age of prostitutes is low. Indeed, the different groups involved in the business of women prostitution focus on requirements which are best for their workplaces such as an individual's nationality, indigeneity and age. It is noted that because exploitation is limited to a certain age range and such women are exposed to a lot of mental and physical sufferings, they are initiated into the process at the lowest possible age. This is done for two purposes: timely excluding them from the job cycle, and maximising the possible profits (Alasvand, 2006).

As previously mentioned, women who are targeted for dealers and traffickers include:

(i) those who undertake prostitution because of economic poverty, and are prepared to endure the problems of the job, until they find a new one;

(ii) those suffering from illiteracy and poverty, and who were born in poor families;

(iii) those who are forced into prostitution;

(iv) those who enter the job voluntarily and accept the associated social exploitation and violence because of their personality vacuum. This group underestimates their own talents, IQ and skills, which renders them good victims for traffickers; and

(v) those who have been unsuccessful in competing with peers during childhood and have received poor support from parents, teachers, and employers (Maknoun \& Ataei Ashtiyani, 2005).

The most important types of forced prostitution are as follows;

\subsubsection{Sexual Tourism}

The tourism industry was introduced by the UN General Assembly, the Universal Bank and some organisations in the United States as one of the means for income generation and debt repayment by poor countries (Hodges, 2006). The emergence and cancerous growth of tourism gave rise to sexual tourism. Sexual tourism means the sexual abuse of women by foreign passengers, traders or tourists in destination countries. In the developing world, sexual tourism constitutes a major part of the tourism industry. "Sex haven" is the term specially ascribed by foreign tourists to Southeast Asian countries such as Thailand in this regard. As tourism is a high-income industry, host governments support it directly (Fehresti \& Sarchamani, 2009).

In determining their tourism policies, countries may support or stop the spread of prostitution as an aspect of 
tourism. Of course, some countries are known for engaging in the sale of women's organs as a means of revenue generation. In promoting the sex industry, more women and girls in cities or countries have been sold to foreign sex tourists.

In sexual tourism involving travels to other countries, men do not experience constraints like the ones existing in their home countries and enjoy trips to exciting places. In foreign countries, men expose women and girls to sexual abuses through troublesome and often dangerous methods. Severe ethnic discriminations, harassments of women, the prominence of powerful countries and economic exploitation have all united to encourage the trade of attractive and sexy women. By turning prostitution into a form of tourism, it has come to be recognised as one of the factors for economic development in poor countries (Hodges, 2006).

In countries known as sex business centres such as Thailand, Brazil, Kenya and Jamaica, thousands of foreign tourists plan annually to spend their free time with poor women and children to meet their sexual desires. Given its growing prevalence, sexual tourism is now a well-known topic in human rights discourses (Alsan, 2005).

The former UN High Commissioner for Human Rights, Mary Robinson, at the UN Conference on Racism held in South Africa in 2001, declared that:

"Trafficking is intrinsically discriminatory. For trafficking in the universal sex industry, we are talking about men who live in relatively well-off countries and pay money in exchange for having sexual relations with women, girls, and even occasionally, boys and men in poor countries. It is beyond issues related to labour law or unequal development problems. This is related to human rights because it includes a prominent and dangerous form of discrimination" (Uniate Nation, 2001).

It is worth pointing out that sex tourists are not usually involved in trafficking. They are financially very rich and are only seeking for a variety of sexual relationships. Although sex tourists generally derive sexual satisfaction from their own legitimate partners, they seek a varied sex life, often due to emotional problems. Also, this type of sexual lifestyle does not saddle them with any permanent responsibility. However, they eventually find out that sexual relationships with prostitutes do not free them from emotional strain. The emotional fulfilment is not achieved and the whole experience turns out to be elusive.

Sex tourists usually have one of two reasons for indulging in unlawful sexual relations as below:

(i) they want to humiliate prostitutes and portray them as unfortunate, miserable and lowly victims. So they harass them and try to engage in the types of sexual acts which ordinarily would not be possible with their wives, or legal sexual relations; or

(ii) they consider themselves as redeemers of women and girls by having relations with them. Here, they create conditions such as "falling in love "or "heroics", and in this way, reclaim these sexual relations from being unlawful to lawful (Rostamzadeh, 2016).

That is why among some men in South-east Asia who have gotten married to two women, the second one is often the result of such unlawful relations. In such cases, they consider themselves not only as redeemers, but they also gain control over favoured victims. (Fehresti \& Sarchamani, 2009).

Sex tourism is unlike women trafficking because individuals meant for women trafficking are carried from one country to another for sexual exploitation while, for sex tourism, it is the reverse because the sex tourist has to go to some other country and have a sexual relationship there. However, sex tourism is typically a reason for the spread of women trafficking. This is because as a place develops into a centre for sex tourists, it will become a special destination to be exploited by traffickers, who will send victims there to look for customers and earn money (Fehresti \& Sarchamani, 2009).

\subsubsection{Pornography}

Pornography refers to paintings, writings or objects that run against morals on sexual issues. It concerns sensuous paintings, writings or devices that provoke sexuality. In pornography, there are visible and invisible actors. An example of the visible actors are manufacturers of sex toys, who lack or are careless about intellectual, human and moral values. They are concerned only about profits and other financial interests. The invisibles are the authorities, which allow sexually-provoking materials to be produced and distributed (Kaveh, 2007).

Similar to sex tourism, communication technologies also feature prominently in issues relating to pornography. Although generally accepted as a useful medium for the expression of thoughts, views and exchange of messages, mass communication technologies have also had some adverse consequences, and studies on them present some of the most 
complicated discourses in social pathology. Today, advances in communication technologies have ushered in notions such as "communication age" and "global village." For example, McLuhan sees the world as a universal village, stating that "mass communication instruments are so strong that they can create new in the course of human history which are very different from past generations" (Sotoudeh, 2010).

Today, pornography has been significantly developed by communication technologies such that it transcends the control of state entities and institutions. Some Internet sites earn $50-80 \%$ of their profits annually simply by directing users to the sex industry or pornography services. Alongside its profitability for the industry, pornography has adverse consequences. A report by an NGO, the World Coalition Against Trafficking in Women in Asia and the Pacific notes that in this age, we are living in a pornography culture in which corruption has been significantly manifested in the production, sale and consumption of women's bodies; A practice that has become more common in recent decades. In addition, "gender" has emerged in different forms of pornography or "sexual recreation" and prostitution. The extent to which these developments affect women's position needs to be seriously examined. An obvious insight gained from the spread of pornography is that women's position has been lowered in society (Maknoun \& Ataei Ashtiyani, 2005).

Pornography, as a cultural activity, was published with written mass products as far back as the 19th century. European historians acknowledge that contemporary pornography has emerged since the establishment of modern democratic states and the development of industrial and investment economy in Europe. However, moralists, from the secular to the religious, have condemned pornography because of its destructive effects on children's sexual moral and public decency, and characterised it as lacking scientific, political and artistic value. Generally, pornography has emerged as the byproduct of technology and is now virtually out of institutional control. In the mid1990s, the Internet was the best tool for the dissemination of pornography. In early September 1995, there were 101,908 pornographic materials on the Internet. Out of that number, 26,055 had existed before July 1995, that is, two months prior, and 72,706 before 1994, meaning 9 months earlier. On the Internet, sex industry advertisements are more common than other forms of advertisements.

\subsubsection{Sex Trafficking}

Slavery has a long history. In earlier historical periods, the trading of humans was by way of slavery. During those periods, state authorities not only failed to oppose slavery, they, in fact, engaged in the practice. As societies developed, slavery, hitherto a fully accepted phenomenon, gradually became a moral sin, and eventually an international crime (Habibzadeh, Moghadasi, \& Jafari Doulat Abadi, 2000).

Sex trafficking is one of the forms of human trafficking. Paragraph 3 of Article 1 of East Asia Union Convention, enacted in Kathmandu in 2002 (SAARC), states that:

"'trafficking" means the moving, selling or buying of women and children for prostitution within and outside a country for monetary or other considerations with or without the consent of the person subjected to trafficking"(East Asia Union Convention, 2002).

Also, the preamble of the 1949 Convention for the Suppression of Trafficking in Persons And of the Exploitation of the Prostitution of Others states that "human trafficking by way of prostitution is contrary to the status of humankind and exposes the safety of society and family to risk." Further, by virtue of Article 4 of the Universal Declaration of Human rights, it is not possible for someone to remain as a slave; and slavery in any form is forbidden (Alsan, 2005).

The strata susceptible to trafficking are growing, apart from women, who are the most trafficked victims. There are also economic migrants or political refugees, who have lost their jobs and properties due to natural disasters, famine, civil war, political instability and diseases such as AIDS. Thus, general economic hardship, forces them to seek for new job opportunities or improved welfare elsewhere and they become good victims for human traffickers (Maknoun \& Ataei Ashtiyani, 2005).

Violence against women by men within the family or otherwise by near relatives is also a common factor due to socio-cultural norms and rules entrenching men's dominance. However, there are other factors that make the situation doubly severe for migrant and trafficked women and render them more vulnerable. One of such factors is living in different and often contradictory cultures. Another is life in isolation as aliens in a foreign country. Most importantly is that such women with no identifications are unstable. Also, it usually imposes legal constraints on them (Salimi, 2004). These numerous factors have influenced the growth and spread of women trafficking in the past decades. The most important of those factors are increased sexual tourism, cultural and economic poverty, the high profit accruing from trafficking activities, the predominance of violence culture, social discriminations, lack of identifications, lack of security and safety at 
both family and national levels, particularly at times of armed conflicts, crisis in moral and value systems, lack of proper and efficient rules to combat traffickers, facilitated trafficking, and schemes such as the Schengen Agreement, which has eased movement across borders (Habibzadeh et al., 2000). Iran, as a neighbour to Afghanistan, Pakistan, Turkey and Arabic countries to which women are often being trafficked, is exposed to human trafficking (Fehresti \& Sarchamani, 2009).

\section{Conclusion}

The main difference between forced and consensual prostitution is that consensual prostitutes earn income directly, and their income is sometimes very high, whereas in forced prostitution, prostitutes have no direct contact with customers and do not earn as much since a significant part of their income goes to the procurers, brothels and other actors involved in the prostitution business. They are rightly seen as sex slaves. Also, the profits generated flow to corrupt dealers. Perhaps that is why some international assemblies such as those in Frankfort in 1991 and Nottingham in 1993, agitated for the improvement of career opportunities for prostitutes, especially social security. There are different reasons for the emergence of women prostitution but economic, social and mental factors more influential. Prostitution results in many cultural, social and economic problems in society, including negative and destructive consequences at both family and personal levels.

\section{References}

Alasvand, F. (2006). Prostitution, Realities and Necessities in Islamic System and Prostitution Issue. Women Researches and Studies Journal, 1(1), 133-178.

Alsan, M. (2005). Trafficking in Women and Children for Sexual Exploitation - From Universal Ban till Support of Victims. Social Welfare Journal, 16(4), 329-364.

Ashouri, M., \& Ravaei, A. (2010). Street Prostitutes and Family. Law Journal, 40(1), 1-20.

Atasheneh, M., Basiri Nia, A., \& Ebrahimi Nasab, Y. (2012). Study of Factors on Sexual Crimes against Women in Iranian Criminal Law. Women and Culture Journal, 11(3), 99-109.

Bastani Parizi, M. E. (2001). Social History in Kātun-e Haftqal'a. 6th Edition. Tehran: Dehkhoda Publication.

Convention for the Suppression of the Traffic in Persons and of the Exploitation of the Prostitution of Others, (1949). Approved by General Assembly Resolution 317 (IV). Retrieved from http://www.ohchr.org/EN/Professionallnterest/Pages/TrafficlnPersons. aspx (December 2, 1949).

Convention on Preventing and Combating Trafficking in Women and Children for Prostitution (SAARC), (2002). Retrieved from http://www.humantrafficking.org/publications/424 (15 January 2002).

Durant, W. (1997). Civilization history. Vol. 2. Trans. by Ahmad Aram. Tehran: Cultural and Scientific Publication.

Fatehi, A., Sadeghi, S., \& Ekhlasi, E. (2010). Description Psychological and Sociological of Women Prostitutes in Isfahan. Iran Social Researches Journal, 10(2), 86-105.

Fehresti, Z., \& Sarchamani, Z. (2009). Human Trafficking and Investigation of Jurisprudentially Views. Specialized Civilization and Jurisprudence Journal, 22(6), 192-218.

Goldouzian, I., \& Pour Ebrahim. A. (2012). Investigation of Women Trafficking in International Documents and Iranian Penal Code. Female Police Studies Journal, 17(6), 109-141.

Habibzadeh, M. J., Moghadasi, M. B., \& Jafari Doulat Abadi, A. (2000). Human Trafficking in Iranian Penal Code. Comparative Law Researches Journal, 4 (13), 99-123.

Haji Deh Abadi, M. A. (2006). Analytical Investigation of Cultural-Educational Factors on Prostitution with Considering Religious Texts, In Islamic System and Prostitution Issue. Women Studies and Researches Journal, 1(1), 179-208.

Hayati, N. S. (2004). Prostitution A Pathologic Event. Psychological Healthy Journal, 10(1), 40-45.

Hodges, D. (2006). Sex Tourism on the Internet. Siyahat Gharb Journal. 27(1). 37-42.

Kaveh, S. (2007). Pornography, Film and Photo. $1^{\text {th }}$ Edition. Tehran: Sokhan Publication.

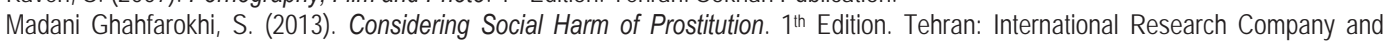
Yadavaran Publication.

Madani Ghahfarokhi, S., Roshanfekr, P., \& Madah, H. (2010). The Comparison of the Characteristics among Adult and Children Prostitutes in Tehran. Iranian Social Concern Investigation Journal, 3 (1), 103-122.

Madani Ghahfarokhi, S., \& Roshanfekr, P. (2013). Women Street Prostitutes Views on Customers Characteristics in Tehran. Social Welfare Journal, 34 (9), 33-64.

Maknoun, S., \& Ataei Ashtiyani, Z. (2005). Feminism and Prostitution. Women Social-Cultural Council Journal, 28 (1), 212-253.

Mohseni, M. (2011). Sociology of Social Deviations. $2^{\text {th }}$ Edition. Tehran: Tahouri Publication.

Moslemi Bidhendi, P., Agha Bakhshi, H., \& Esmaeili, I. (2012). How To Satisfy Women's Affection Needs by Men and Their Role in Women Prostitution. Social Research Journal, 19(6), 65-82.

Rahimi Far, M. (2005). An Investigation of Women's Position in Ancient Time. History Research Journal, 24(1), 55-77. 
Rahmani, A. (2009). The Victims of Social Diseases. Social Pathology Journal, 17(1), 32-33.

Rostamzadeh, E. (2016). Prevention of Prostitution among Iranian Women: A Domestic and International Law Resolutions. (Unpublished Doctoral Dissertation). National University of Malaysia, Bangi Selangor, Malaysia.

Safari, N. (2013). Statistic of Street Women. Retrieved from http://www.tebyan.net/newindex.aspx?pid=213753 (22 February 2013).

Salimi, S. (2004). Human Trafficking as an International Organized Crime. Political and Law University Journal, 64(1), 37-58.

Samadi Rad, A., \& Saberi, Z. (2008). Prostitution and Social Security, Disciplinary and Social Security Journal, 3(1), 81-100.

Sharifi Khezarati, A. (2010). Sexual Perversion - A Comparative Study on Criminology and Jurisprudence. $2^{\text {th }}$ Edition. Tehran: Andisheh Asr Publication.

Sotoudeh, H. (2010). Social Pathology. 22 $2^{\text {th }}$ Edition. Tehran: Avaei Nour Publication.

Stephenson, J. (2000). Women's Roots: The History of Women. $5^{\text {th }}$ Edition. Nevada: Diemer Smith Publishing Company.

World Conference against Racism, Racial Discrimination, Xenophobia and Related Intolerance, (2001), Retrieved from http://www.undocuments.net/durban-d.htm (8 September 2001).

Yaqin, A. (2007). Legal Research and Writing, $1^{\text {th }}$ Edition, Lexis Nexis Publications, Kuala Lumpur, Malaysia. 